\title{
The spatial ecology of invasive feral cats Felis catus on San Cristóbal, Galápagos: first insights from GPS collars
}

\author{
A. MacLeod ${ }^{1}$ (D) - S. C. Cooke $^{2}$ (D) F. Trillmich ${ }^{3}$ (D) \\ Received: 3 May 2019 / Accepted: 30 March 2020 / Published online: 17 April 2020 \\ (C) The Author(s) 2020
}

\begin{abstract}
The dangers posed by invasive species for endemic island wildlife are well recognised. Introduced domestic cats (Felis catus) represent a significant threat to several endemic species of the Galápagos archipelago-including hatchling marine iguanas (Amblyrhynchus cristatus) and potentially green turtles (Chelonia mydas) - yet little is known about their spatial ecology and habitat use on these islands. Here, we describe a pilot study using GPS collars to track the movements of three feral cats at a site of conservation interest on San Cristóbal Island. Based on 175 days of GPS data, we undertook spatial analyses to ascertain home ranges, and to investigate the overlap of ranges between the cats and potential prey species. Average home range was $1.27 \mathrm{~km}^{2}$ $\left(1.12-1.46 \mathrm{~km}^{2}\right)$, which — though small for feral cats - is in keeping with previous findings in Galápagos. We found the cats did use the habitat of a small marine iguana population but did not change their spatial habits before and after iguana hatchlings appeared. Changes over time in the daily movements of one cat indicated a possible response of the individual to the presence of hatchling green turtles (Chelonia mydas); though the data here are insufficient to show whether the cat was hunting these hatchlings. We recommend similar work be undertaken in areas with larger marine iguana populations, where hatchlings could represent a potentially important food source for invasive feral cats, as well as further work to determine the threat posed by cats to turtle hatchlings in Galápagos.
\end{abstract}

Keywords Home range $\cdot$ Conservation $\cdot$ Introduced predators $\cdot$ Chelonia mydas $\cdot$ Amblyrhynchus cristatus

\section{Introduction}

The negative impact of invasive species on endemic wildlife is well recognised. This influence can be particularly strong on islands, where vulnerable biological assemblages may be rapidly decimated by an influx of non-native species (Vitousek 1988). Invasive species are the primary cause of extinctions

Communicated by: Krzysztof Schmidt

A. MacLeod

ms.amymacleod@gmail.com

1 Unit for Molecular Evolution and Systematics of Animals, Institute of Biology, University of Leipzig, Talstrasse 33, 04103 Leipzig, Germany

2 Conservation Science Group, Department of Zoology, University of Cambridge, Downing St, Cambridge CB2 3EJ, UK

3 Department of Animal Behaviour, University of Bielefeld, Morgenbreede 45, 33619 Bielefeld, Germany on islands (Doherty et al. 2016) and the devastating effects of introduced predators on such systems have been seen worldwide (Reaser et al. 2007; Spatz et al. 2017), including in the Hawaiian Archipelago (Boyer 2008), the Azores (Bried et al. 2009), and New Zealand (Russell et al. 2015). Domestic cats (Felis catus) have been implicated in reductions of 25 threatened reptile species worldwide (Medina et al. 2011).

The Galápagos archipelago is limited in terms of native mammals - as is common in remote island chains - and endemic Galápagos species have evolved in the absence of larger terrestrial mammalian predators. These island endemics demonstrate little wariness (Berger et al. 2007) and are therefore particularly vulnerable to predation by black rats (Rattus rattus), domestic cats and dogs (Canis familiaris) (Cayot et al. 1994). These introduced animals were originally brought to the archipelago by people, and today are found feral on many of the islands. A full understanding of the effects of these introduced species is not yet available. However, it is suspected that they put many species of conservation concern at risk of population reduction or extirpation (Konecny 1987a; Cayot et al. 1994; Wikelski and Nelson 2004). 
The Galápagos marine iguana (Amblyrhynchus cristatus) is an emblematic endemic species of the Galápagos archipelago. The species is recognised as vulnerable to extinction by the International Union for the Conservation of Nature (IUCN; Nelson et al. 2004). Although marine iguanas are monitored, robust estimates of current population sizes for most islands are lacking. On San Cristóbal, marine iguana populations are thought to be the smallest of any island, and the colonies around Punta Pitt in the northeast are likely to be critically small ( $<500$ adults; MacLeod et al. 2016). A recent taxonomic revision (Miralles et al. 2017) has recognised the animals from these colonies as a new subspecies, the Godzilla marine iguana (A. c. godzilla). This subspecies delimitation, together with recent population size estimates, indicates that the colonies around Punta Pitt are the single highest priority for protection from anthropogenic threats (MacLeod and Steinfartz 2016), including introduced predators.

Feral cats on the Galápagos are known to have broad diets including rodents, birds, crabs, arachnids, beetles, grasshoppers, lizards and fish (Konecny 1983). As in many other locations, feral cats here preferentially select rodents when available; but lizards and birds are also common prey items (Konecny 1983). The density of introduced black rats (Rattus rattus; the only rodent likely to be found in the study location) is highly dependent on the local habitat type and vegetation density, with arid coastal zones harbouring far smaller populations than montane forests, especially before the rains of the wet season arrive-usually beginning in July (Clark 1980). Though lava lizards appear to be the main reptilian prey, feral cats are also known to predate hatchling and young Galápagos marine iguanas (Cayot et al. 1994; Konecny 1983) and are suspected to be a serious threat in affected populations (Laurie 1983). Observations from researchers working at Punta Pitt in the 1980s onwards indicate that marine iguana populations in this area have been critically small since at least this time (Laurie 1983; Wikelski and Nelson 2004; MacLeod and Steinfartz 2016), and that feral cats were also present and numerous then (WA Laurie, pers. comm.). Given the apparent abundance of suitable food sources and nesting substrate at this locality (A. MacLeod, pers. obs.), the small population size of marine iguanas at Punta Pitt is a somewhat enigmatic situation. However, feral cat predation is strongly suspected which our study aims to investigate.

Rapid advancements in the development of tracking equipment now allow the deployment of smaller collars which can remotely track feral domestic cats. These have much to offer in terms of enhancing our understanding of their movement ecology, daily activity patterns, and possible interactions with other wildlife. Herein, we describe a small-scale pilot study which attempts to investigate the movements of feral cats within the vicinity of one key population of Galápagos marine iguanas. Since it is the iguana hatchlings that are known to be predated by feral cats, we focused on observing cats around the hatching season of the marine iguana. Specifically, we were interested in whether the spatial ecology of the cats changed in response to the hatching of the iguana eggs. As feral cats on the Galápagos must respond to seasonal fluctuations in prey availability (Konecny 1983), our hypothesis was that cats alter their habitat use once the hatchling iguanas began to emerge, to take advantage of this new prey item. We therefore fitted feral cats with GPS collars shortly before the marine iguana hatching season and continued to track them once hatchlings had started to emerge. To answer the question of whether there was an observable change in the habitat use of these cats once marine iguana hatchlings emerged, we then compared the cats' movements both before and after this event. Whilst the core aim of this project was to focus on feral cats within marine iguana habitat, we extended this aspect to look at other species that occupy distinct areas within the cats' range and may also be affected by them. These include green turtle hatchlings (Chelonia mydas) and the redfooted booby (Sula sula). Both species were actively nesting during the time of the study. In the case of the green turtle, hatching events were extremely common during the study (hatchlings emerged from multiple nests during most early evenings and nights), and thus may provide abundant potential prey for the cats (Seabrook 1989) during these times. Though several other small species of potential conservation concern including lava lizards (genus Microlophus, near threatened), racer snakes (Pseudalsophis biserialis, data deficient), Darwin's finches (family Thraupidae, varied statuses), lava gulls (Leucophaeus fuliginosus, vulnerable) and Chatham mockingbird (Mimus melanotis, endangered) were all recorded in the area covered by the study, there are insufficient data regarding nesting locations and ranges of these species to analyse the possible impact of cats on these endemics. We also aimed to gather basic information regarding the extent of the home ranges of the cats, and whether their nocturnal habits differed from their diurnal habits.

\section{Methods}

\section{Fieldwork}

We undertook fieldwork between April and July 2013 in the area of Punta Pitt on the north-eastern tip of San Cristóbal (Fig. 1). This area includes a zone of bare sandy beach where turtles nest, a rocky intertidal zone where marine iguanas forage or rest during the day, and a dry scrub zone dominated by Palo Santo trees (Bursera graveolens). The closest source of standing or running fresh water is over $30 \mathrm{~km}$ away. In early May, we fitted four feral cats (two males and two females) with GPS collars (e-obs; Germany $11 \mathrm{C}$ light UHF). The cats were caught using live traps (single door Tomahawk type, $80 \times 25 \times 15 \mathrm{~cm})$, baited daily with sardines. All cats were 
Fig. 1 Location of Galápagos, relative to continental Ecuador, and our field site (shown by the black star)

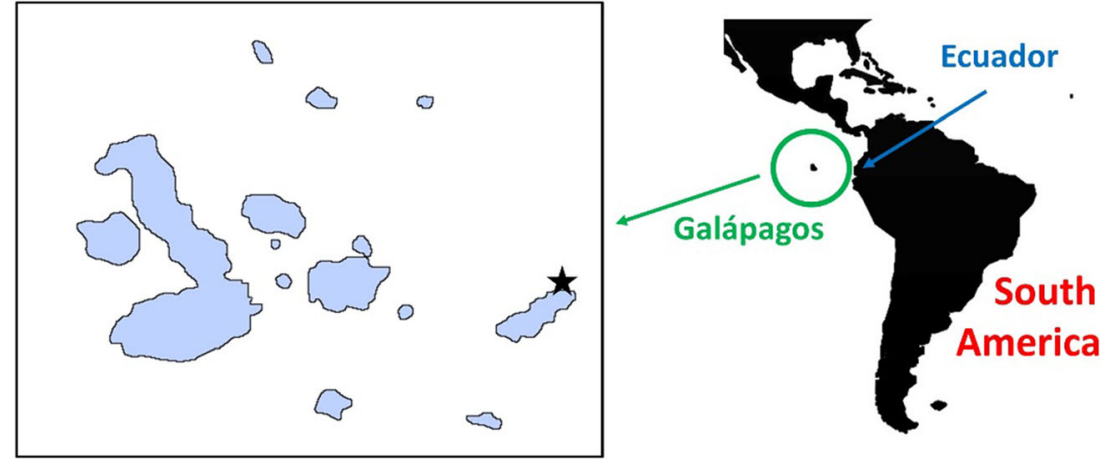

caught within a 1-week period, and the traps were checked thrice daily to minimise potential stress. Due to the remote location, no veterinarian was available for the collar fitting, and so we undertook this work without use of anaesthesia. We weighed the trap together with cat using a spring balance and subtracted the trap weight. We then rapidly fitted the collars (115 $\mathrm{g} ; \leq 5 \%$ of the body weight) with one person restraining the cat using heavy-duty gardening gloves and a thick blanket. After collar fitting, we immediately released the cats. Aside from minor self-inflicted injuries in the traps, all animals appeared completely healthy upon release. To allow the cats to acclimatize to the collars and recover from the stress of the trapping, we discarded the first 3 days of collar data. This period was chosen by viewing the GPS-recorded movements of the four cats, all of whom appear to have resumed normal movements within this 3-day window. We obtained data remotely from a base station (e-obs 1 b5), which automatically downloaded data when the collars were within a close range (probably $<0.5 \mathrm{~km}$ ). If data were not downloaded in this way within 3 days, we radio-tracked the cats to within a working proximity for the data download. We programmed the collars to provide GPS fixes every $30 \mathrm{~min}$ for $24 \mathrm{~h}$ per day; therefore, each day provided up to 48 GPS fixes.

We conducted ground surveys on species of conservation interest (Godzilla marine iguanas, green turtles and red-footed boobies). Locations of interest (sites of adult or juvenile presence and nesting sites) were recorded using a handheld GPS device (Garmin GPSMAP 64st). In addition, we recorded the location of a shallow salt lake, which attracted several species of small birds, including the black-necked stilt (Himantopus mexicanus), sanderlings (Calidris alba) and whimbrels (Numenius phaeopus), as it provided a potentially rich hunting ground. To ascertain the date at which marine iguana hatchlings began emerging, we undertook daily surveys of the colonies until 1st June whilst we were engaged in other fieldwork in the local area, then surveyed every 3 days until the first hatchlings were confirmed. On 7th June, we encountered the first hatchlings, which were estimated to be less than 1-weekold based on consultation with the local expert wildlife veterinarian. As turtles were not the initial focus of this work, our observations of nest emergence are somewhat more ad hoc; during a field camp (early April to early June) in the vicinity of the nesting beaches, we observed regular nightly emergence of hatchlings. However, from the literature, we see that green turtle hatchlings are known to mostly $(>86 \%)$ emerge after darkness (Pritchard 1971; Glen et al. 2005). Nesting period on the Galápagos is from December to June peaking in February (Arteaga and Guayasamin 2019), with emergence around 55 days after egg deposition (Zárate et al. 2013). Therefore, our observations are in keeping with other studies and the timing of our data collection coincides with the peak emergence of hatchling green turtles.

\section{Analysis}

We spatially analysed the data using ArcMap 10.5.1 and Rx64 3.4.4 with the package "adehabitatHR" (Calenge 2015). We first removed GPS points with a horizontal accuracy of over $20 \mathrm{~m}$, which made up a mean of $10 \%$ of data points for each cat. We then used kernel density estimation (Campbell et al. 2013; Lichti and Swihart 2011) to produce home (95\%) and core (50\%) ranges for each cat from their recorded GPS fixes. To identify the bandwidth that produced consistently sensible home and core ranges without lacuna for the full datasets as well as analysed subsets, we used an ad hoc method of smoothing parameter selection, as recommended by Kie (2013). This resulted in the use of a bandwidth of $0.9 * \mathrm{href}$ (the reference bandwidth). We then clipped these ranges to the extent of the island and identified the intersections (overlapping areas) between them. We also produced home and core night and day ranges for each cat, with the cut-offs between the two at 06:00 and 18:00. We then identified the intersecting areas between the night and day ranges for each cat.

\section{Surveys of potential prey}

We mapped the locations of a red-footed booby nesting area and the salt lake containing multiple waterbird species and compared them to the recorded locations and ranges of the cats. The areas of two marine iguana colonies were mapped by creating separate buffer zones which extended $250 \mathrm{~m}$ in from the coastline - the maximum distance of nesting 
observed - between the range limitation coordinates recorded in the field for each colony. We used satellite imagery from ArcGIS's World Imagery (ArcGIS 2019; chosen as this provided cloudless images for our study area at a resolution of $0.5 \mathrm{~m}$ ) to identify an outcrop of higher altitude (up to $95 \mathrm{~m}$ ). We excluded this area from these buffer zones as we presumed it to be unsuitable habitat for marine iguanas, and none had been seen here during many foot surveys. We then identified the overlap between these iguana areas and the ranges of the cats. In addition, we compared cat activity in these areas before and after the estimated iguana hatchling emergence start date of 1 st June. The regions of green turtle nesting sites found during regular foot surveys were selected on the satellite images; these were areas of coastal sand or patchy sand with scrub. We then analysed the activities of the cats in these areas, during the time of day at which turtle hatchlings emerged (18:00-22:00; as seen by direct observation and from the literature; Salmon and Reising 2014). For one cat which showed a high level of activity in this area, we produced another core range using only GPS fixes recorded during this time window and compared it to the core range determined for the whole period of observation.

\section{Results}

\section{Data obtained}

We caught in total four cats (two females and two males)though we used baited traps set from mid-April, all captures occurred within 1 week in early May. Of the four cats, the last cat collared (a female) was younger and smaller than the other three, and since the data collected for this cat was very shortterm (24 days) and showed significantly shorter-range movements than the others, we chose to disregard these data on the grounds that they appear not to be representative for adult feral cats. A summary of the GPS data collected for the three cats is given in Table 1.

\section{Home ranges and general habitat use}

The home ranges of the cats ranged from 1.12 to $1.46 \mathrm{~km}^{2}$ with $1.27 \mathrm{~km}^{2}$ being the mean value (Table 2). Cats C2417

Table 1 Basic information on data collected using GPS collars from the three cats

\begin{tabular}{llll}
\hline Cat ID & Sex & Data period & Days of GPS data \\
\hline C2417 & Female & $06.05 .2013-15.08 .2013$ & 103 \\
C2418 & Male & $07.05 .2013-13.06 .2013$ & 38 \\
C2419 & Male & $11.05 .2013-13.06 .2013$ & 34 \\
\hline
\end{tabular}

Table 2 Area of the home (95\%) and core (50\%) ranges estimated for all three cats using kernel density estimation

\begin{tabular}{lll}
\hline Cat ID & $95 \%$ range $\left(\mathrm{km}^{2}\right)$ & $50 \%$ range $\left(\mathrm{km}^{2}\right)$ \\
\hline $\mathrm{C} 2417$ & 1.46 & 0.22 \\
$\mathrm{C} 2418$ & 1.24 & 0.32 \\
$\mathrm{C} 2419$ & 1.12 & 0.39 \\
\hline
\end{tabular}

(female) and C2418 (male) had larger home ranges than C2419 (male), but the core range for C2419 was larger than that of the other two cats, implying increased consistency in its use of the area available to it. There was very little difference between the nocturnal and diurnal ranges of each cat, with the home ranges overlapping by an average of $86 \%$ of the area. Only one cat, C2419, showed high variation in its diurnal and nocturnal area use, but only at the core range level, which overlapped by only $35.1 \%$ between day and night. The home ranges of all three cats overlapped and the range of the smallest (therefore possibly the youngest) cat, $\mathrm{C} 2419$, existed in the middle of those of the other two (Fig. 2). Cats C2418 and C2419 showed the largest overlap of $36 \%$ of the total area covered by their home ranges (Table 3); the core ranges of cats $\mathrm{C} 2417$ and C2419 also overlapped.

\section{Overlap between cat ranges and selected species of interest}

\section{Red-footed boobies and other waterbirds}

The recorded red-footed booby nesting area was not within any of the home ranges of the cats. GPS fixes of only one cat, C2418, came within $500 \mathrm{~m}$ of the nesting area and only one of its fixes was somewhat close (101 m away). The salt lakewhich attracted multiple waterbird species - did sit within the home range of cat C2417 and partially overlapped with its core range, but the GPS fixes for that cat did not appear to cluster around its edge in comparison with other areas. The home range of the second nearest cat, $\mathrm{C} 2419$, was $110 \mathrm{~m}$ from

Table 3 The extent of overlap between the home (95\%) ranges of each cat and the core $(50 \%)$ ranges, produced by dividing the area of the intersect by that of the union of each pair of ranges

\begin{tabular}{llc}
\hline Cats' IDs & \multicolumn{2}{c}{ Percentage overlap } \\
\cline { 2 - 3 } & $95 \%$ range & $50 \%$ range \\
\hline C2417 and C2418 & 7.1 & 0.0 \\
C2417 and C2419 & 30.3 & 13.0 \\
C2418 and C2419 & 35.6 & 0.0 \\
\hline
\end{tabular}


the lake at its closest point. It did pass by the lake on one occasion and was recorded at $6 \mathrm{~m}$ from it, but did not stay in the area for long, being recorded in a different location $30 \mathrm{~min}$ later.

\section{Galápagos marine iguanas}

The home and core ranges of all three cats overlapped to some extent with one or both iguana colonies (Fig. 2). The average overlap of the home and core ranges with the iguana ranges was $11.9 \%$ and $6.2 \%$ respectively (Table 4 ). The home range of $\mathrm{C} 2418$ had one outlying area, which overlapped precisely with a recorded iguana nesting area (Fig. 2 ). This cat made five separate visits to this area on 10,14 and 20 May and 2nd and 12 June. All visits were between 01:30 and 09:00.

Although the exact date of iguana hatching in this area was unknown, frequent surveys allowed the estimation of a date (1 June) which was likely within a 3-day window of the first hatchings. When comparing home and core ranges created using only GPS fixes from before, or from after, the 1 June, for each cat, we found that there was very little change in the overlap of the before and after ranges with the iguana areas (Table 4).
Table 4 The extent of overlap between the home (95\%) and core (50\%) ranges of each cat and the area used by iguanas, produced by dividing the area of the intersect by that of the union of the two ranges, along with the change in overlap extent before and after the estimating hatching date of 1 June

\begin{tabular}{lccccc}
\hline Cat ID & \multicolumn{2}{l}{$\begin{array}{l}\text { Percentage overlap with } \\
\text { iguana area }\end{array}$} & & \multicolumn{2}{l}{$\begin{array}{l}\text { Change in percentage overlap } \\
\text { after hatching date }\end{array}$} \\
\cline { 2 - 3 } \cline { 5 - 6 } & $95 \%$ range & $50 \%$ range & & $95 \%$ range & $50 \%$ range \\
\hline $\mathrm{C} 2417$ & 9.0 & 8.1 & & 1.9 & -1.6 \\
$\mathrm{C} 2418$ & 18.0 & 5.5 & & 3.3 & 2.4 \\
$\mathrm{C} 2419$ & 8.8 & 5.0 & -1.2 & 1.6 \\
\hline
\end{tabular}

\section{Green turtles}

Of the three cats studied, C2417 had a home range that overlapped significantly with the recorded green turtle (Chelonia mydas) nesting areas, with $23 \%$ of GPS fixes within the nesting zone. Our observations of these nests indicated high hatching activity in the early evening in keeping with published data for this species (Salmon and Reising 2014). When the movements of $\mathrm{C} 2417$ during the early evening (defined as 18:00-22:00) were considered in isolation, the proportion of GPS fixes within the nesting

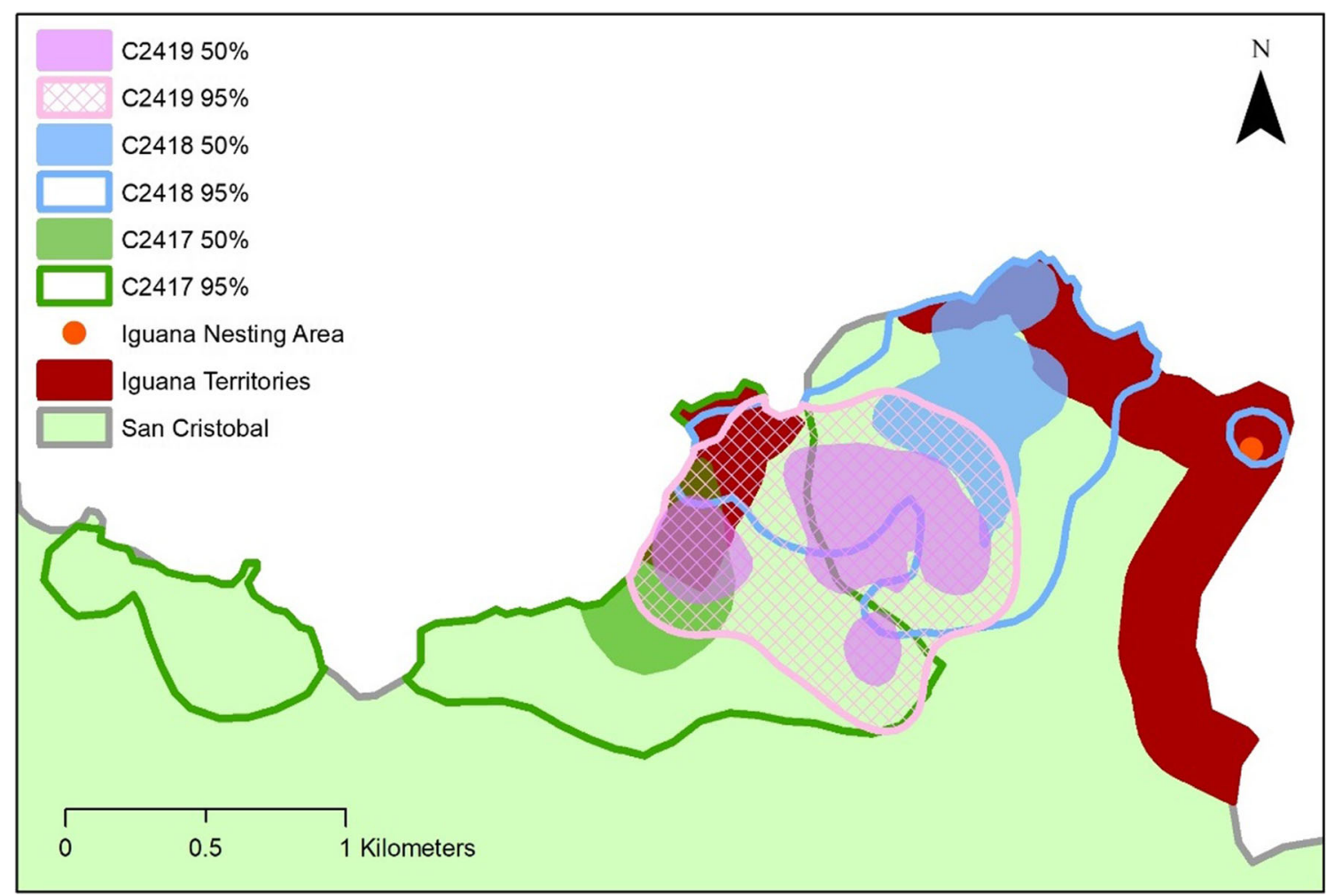

Fig. 2 The locations of two marine iguana territories and one nesting area, overlaid with home (95\%) and core (50\%) ranges for one female (C2417) and two male (C2418 and C2419) cats tagged with GPS collars on the north east tip of San Cristóbal 
area rose to $59 \%$. Twenty-eight percent of the core range created only from the GPS fixes within the early evening time frame overlapped with the turtle nesting area, compared with $18 \%$ of the original core range encompassing all the fixes for this cat (Fig. 3).

\section{Discussion}

Although the territories of the cats overlapped with the marine iguana ranges, we did not see a clear change in feral cat habitat use around the estimated time of iguana hatching. We are therefore unable to confirm or reject our original hypothesis. This is likely in part due to the limitations of our small-scale dataset but could also be due to the size and demography of the marine iguana population studied. Of all the islands on which the marine iguana occurs, the smallest population is found on San Cristóbal (Wikelski and Nelson 2004). Though reasons for this are unclear, the fact that San Cristóbal is considered to be the most human-modified island of the archipelago (Watson et al. 2010) might indicate the influence of anthropogenic threats. Feral cats are perhaps the most pressing of those threats, especially at Punta Pitt, a locality at quite a distance from sources of marine pollution and urbanisation. The small size of the marine iguana population at this location and the particular paucity of young iguanas may indicate that — due to their scarcity - the iguanas here do not represent a significant source of food to the cats. To better estimate the impact of cat predation on the marine iguana in general, it may be worth undertaking a larger study at another colony, such as those found on Isabela Island or Punta Nuñez on Santa Cruz, where larger numbers of hatchlings are known, and feral cats also occur. For the Godzilla iguanas on San Cristóbal, analysis of the feral cat's diet via scat samples may yield better results, although such studies in this region are logistically challenging. One pragmatic solution could be to undertake stomach content analysis of cats that are trapped or otherwise killed in control measures during the normal activities of the conservation managers.

Although the feral cats' ranges did overlap with the lake used by waterbirds, the cats spent very little time in this area and so there is little reason to suspect they were hunting here. However, we did find evidence suggestive of cats responding to the presence of green turtle hatchlings. Green turtles are an endangered migratory species that utilises the Galápagos' beaches for nesting. Of the three cats studied, we found one which had over 2.5 times the number of GPS points within the nesting zone during the time of highest hatchling emergence. This could suggest that this cat was predating upon the turtle hatchlings, but without further study, this is only speculation. However, such predation has been described before in other localities (Seabrook 1989) and the great local abundance and vulnerability of hatchling green turtles to cats makes them a probable prey. Though it is possible that the presence of nocturnal black rats attracted to

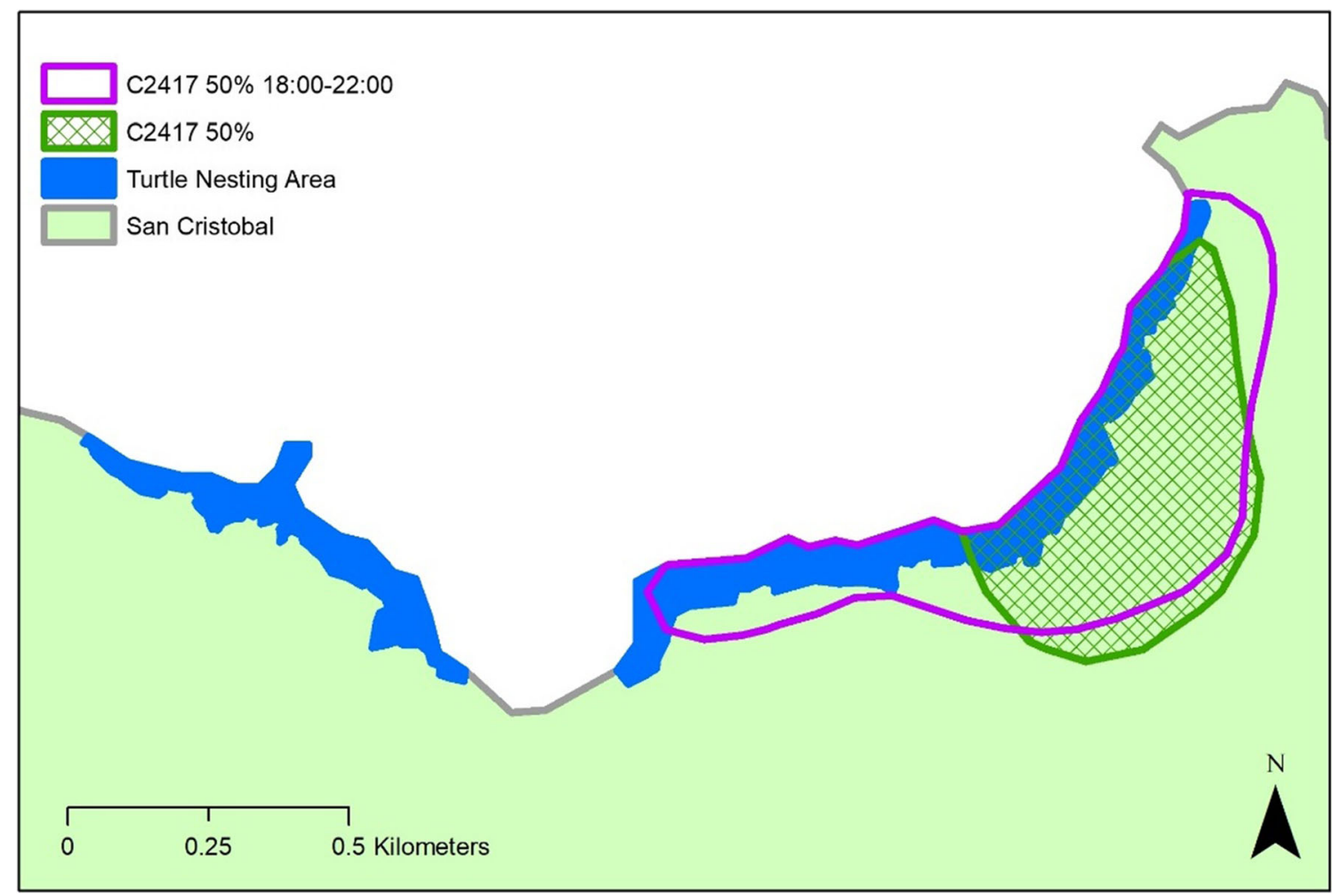

Fig. 3 Core (50\%) ranges for cat C2417 using all GPS fixes and using only those recorded between the hours of 18:00 and 22:00, with comparison to the turtle nesting area 
the turtle nests may have in turn attracted the cat instead; our observations during our 2-month long camp in the area suggest very few rats are found there. Despite daily careful wildlife surveys, we encountered a black rat only once, which appeared to have been attracted to the campsite by our food store. Indeed, rats are relatively uncommon in arid coastal and scrub areas of the Galápagos (Clark 1980) and are presumably far more challenging prey for cats than freshly emerged turtles.

Home ranges of the cats studied were smaller than those reported for other localities, though not markedly so when compared with earlier estimates that specifically concern feral cats in Galápagos; indeed, these values are very similar to those reported for feral cats in Galápagos in the 1980s (Konecny 1987b). Home ranges differed slightly when comparing day and night, with nocturnal ranges being smaller than diurnal ones. Such findings could be useful for efforts to control and eradicate this species, indicating that trapping and other control measures need not cover large areas in order to be effective.

Overall, our pilot study indicates that GPS-based studies of home ranges have great utility in learning about the habits of invasive animals, but such studies should involve a larger sample size to increase the usefulness and wider applicability. To investigate specifically whether feral cats respond to the seasonal availability of marine iguanas, future studies should focus on localities with larger numbers of hatchling iguanas and attempt to positively determine potential prey species through scat analysis. Whilst the smaller iguana colonies are likely to suffer greater effects of predation, the low number of hatchlings in such colonies makes studying the effect very difficult. The results of this study hint that feral cats around Punta Pitt may be responding to emergence of hatchling green turtles and further research should be done to investigate the threat posed by cats to recruitment in this vulnerable species.

Acknowledgements We thank the editor and reviewers for providing invaluable comments to improve this manuscript and Lydia Unsworth for the invaluable assistance in the field. We would like to thank the Charles Darwin Foundation and the Galápagos National Park Directorate (GNPD) who kindly granted us the permission to carry out this investigation under the permit number PC-23-13 and supported us during fieldwork.

Funding information Open Access funding provided by Projekt DEAL. We thank the Galápagos Conservation Trust for providing Funding for this study.

Open Access This article is licensed under a Creative Commons Attribution 4.0 International License, which permits use, sharing, adaptation, distribution and reproduction in any medium or format, as long as you give appropriate credit to the original author(s) and the source, provide a link to the Creative Commons licence, and indicate if changes were made. The images or other third party material in this article are included in the article's Creative Commons licence, unless indicated otherwise in a credit line to the material. If material is not included in the article's Creative Commons licence and your intended use is not permitted by statutory regulation or exceeds the permitted use, you will need to obtain permission directly from the copyright holder. To view a copy of this licence, visit http://creativecommons.org/licenses/by/4.0/.

\section{References}

ArcGIS (2019) World Imagery. https://www.arcgis.com/home/item.html? $\mathrm{id}=\mathrm{c} 03 \mathrm{a} 526 \mathrm{~d} 94704 \mathrm{bfb} 839445 \mathrm{e} 80 \mathrm{de} 95495$

Arteaga A, Guayasamin JM (2019) Chelonia mydas. In: Arteaga A, Bustamante L, Viera J, Tapia W, Guayasamin JM (eds) Reptiles of the Galápagos: life on the Enchanted Islands. Tropical Herping, Quito, pp 124-127

Berger S, Wikelski M, Romero LM, Kalko EKV, Rödl T (2007) Behavioral and physiological adjustments to new predators in an endemic island species, the Galápagos marine iguana. Horm Behav 52:653-663. https://doi.org/10.1016/j.yhbeh.2007.08.004

Boyer AG (2008) Extinction patterns in the avifauna of the Hawaiian islands. Divers Distrib 14(3):509-517

Bried J, Magalhães MC, Bolton M, Neves VC, Bell E, Pereira JC, Aguiar L, Monteiro LR, Santos RS (2009) Seabird habitat restoration on Praia Islet, Azores archipelago. Ecol Res 27(1):27-36

Calenge $\mathrm{C}$ (2015) Home range estimation in R: the adehabitatHR package

Campbell HA, Dwyer RG, Irwin TR, Franklin CE (2013) Home range utilisation and long-range movement of estuarine crocodiles during the breeding and nesting season. PLoS One 8:e62127. https://doi. org/10.1371/journal.pone.0062127

Cayot LJ, Rassmann K, Trillmich F (1994) Are marine iguanas endangered on islands with introduced predators? Noticias de Galápagos 53:13-15

Clark DB (1980) Population ecology of Rattus rattus across a desertmontane forest gradient in the Galápagos Islands. Ecology 61: $1422-1433$

Doherty TS, Glen AS, Nimmo DG, Ritchie EG, Dickman CR (2016) Invasive predators and global biodiversity loss. Proc Natl Acad Sci U S A 113:11261-11265

Glen F, Broderick AC, Godley BJ, Hays GC (2005) Patterns in the emergence of green (Chelonia mydas) and loggerhead (Caretta caretta) turtle hatchlings from their nests. Mar Biol 146(5):1039-1049

Kie JG (2013) A rule-based ad hoc method for selecting a bandwidth in kernel home-range analyses. Anim Biotelemetry 1:13. https://doi. org/10.1186/2050-3385-1-13

Konecny MJ (1983) Behavioral ecology of feral house cats in Galápagos, Ecuador (Doctoral dissertation). University of Florida, Gainesville

Konecny MJ (1987a) Food habits and energetics of feral house cats in the Galápagos Islands. Oikos 50:24-32

Konecny MJ (1987b) Home range and activity patterns of feral house cats in the Galápagos Islands. Oikos 50:17-23

Laurie AWA (1983) Marine iguanas in Galápagos. Oryx 17:18-25

Lichti NI, Swihart RK (2011) Estimating utilization distributions with kernel versus local convex hull methods. J Wildl Manag 75:413422. https://doi.org/10.1002/jwmg.48

MacLeod A, Steinfartz S (2016) The conservation status of the Galápagos marine iguanas, Amblyrhynchus cristatus: a molecular perspective. Amphibia-Reptilia 37:91-109. https://doi.org/10.1163/1568538100003035

MacLeod A, Unsworth L, Trillmich F, Steinfartz S (2016) Mark-resight estimates confirm a critically small population size in threatened marine iguanas (Amblyrhynchus cristatus) on San Cristóbal Island, Galápagos. Salamandra 52:58-62

Medina FM, Bonnaud E, Vidal E, Tershy BR, Zavaleta ES, Josh Donlan C, Keitt BS, Le Corre M, Horwath SV, Nogales M (2011) A global 
review of the impacts of invasive cats on island endangered vertebrates. Glob Chang Biol 17(11):3503-3510

Miralles A, Macleod A, Rodríguez A, Ibáñez A, Jiménez-Uzcategui G, Quezada G, Vences M, Steinfartz S (2017) Shedding light on the Imps of Darkness: an integrative taxonomic revision of the Galápagos marine iguanas (genus Amblyrhynchus). Zool J Linnean Soc 181:678-710. https://doi.org/10.1093/zoolinnean/zlx007

Nelson, K, Snell, H, Wikelski, M (2004) Amblyrhynchus cristatus. The IUCN Red List of Threatened Species: e.T1086A3222951. 10.2305

Pritchard PC (1971) Galápagos sea turtles: preliminary findings. J Herpetol 5:1-9

Reaser JK, Meyerson LA, Cronk Q, De Poorter MA, Eldrege LG, Green E, Kairo M, Latasi P, Mack RN, Mauremootoo J, O'dowd D, Orapa W, Sastroutomo S, Saunders A, Shine C, Thrainsson S, Vaiutu L (2007) Ecological and socioeconomic impacts of invasive alien species in island ecosystems. Environ Conserv 34(2):98-111

Russell JC, Innes JG, Brown PH, Byrom AE (2015) Predator-free New Zealand: conservation country. BioScience 65(5):520-525

Salmon M, Reising M (2014) Emergence rhythms of hatchling marine turtles: is a time sense involved? Chelonian Conserv Biol 13:282285. https://doi.org/10.2744/CCB-1121.1
Seabrook W (1989) Feral cats (Felis catus) as predators of hatchling green turtles (Chelonia mydas). J Zool Soc London 219:83-88. https://doi.org/10.1111/j.1469-7998.1989.tb02567.x

Spatz DR, Holmes ND, Reguero BG, Butchart SH, Tershy BR, Croll DA (2017) Managing invasive mammals to conserve globally threatened seabirds in a changing climate. Conserv Lett 10(6):736-747

Vitousek PM (1988) Diversity and biological invasions of oceanic islands. In: Wilson EO, Peter FM (eds) Biodiversity. National Academies Press, Washington, D.C.

Watson J, Trueman M, Tufet M, Henderson S, Atkinson R (2010) Mapping terrestrial anthropogenic degradation on the inhabited islands of the Galápagos Archipelago. Oryx 44:79-82. https://doi. org/10.1017/S0030605309990226

Wikelski M, Nelson K (2004) Conservation of Galápagos marine iguanas (Amblyrhynchus cristatus). Iguana 11:190-197

Zárate P, Bjorndal KA, Parra M, Dutton PH, Seminoff JA, Bolten AB (2013) Hatching and emergence success in green turtle Chelonia mydas nests in the Galápagos Islands. Aquat Biol 19(3):217-229

Publisher's note Springer Nature remains neutral with regard to jurisdictional claims in published maps and institutional affiliations. 